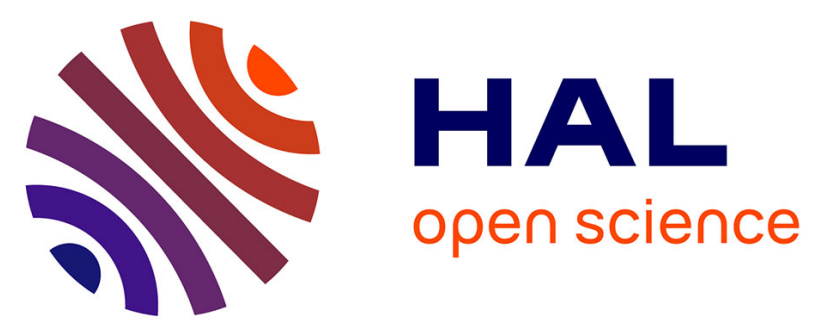

\title{
Reduced risk of cancer among low-dose aspirin users: Data from French health care databases
}

Aya Ajrouche, Yann de Rycke, Marie Dalichampt, David Messika Zeitoun, Jean-Sébastien Hulot, Candice Estellat, Florence Tubach

\section{To cite this version:}

Aya Ajrouche, Yann de Rycke, Marie Dalichampt, David Messika Zeitoun, Jean-Sébastien Hulot, et al.. Reduced risk of cancer among low-dose aspirin users: Data from French health care databases. Pharmacoepidemiology and Drug Safety, 2019, 28 (9), pp.1258-1266. 10.1002/pds.4870 . hal-02284313

\section{HAL Id: hal-02284313 \\ https://hal.sorbonne-universite.fr/hal-02284313}

Submitted on 11 Sep 2019

HAL is a multi-disciplinary open access archive for the deposit and dissemination of scientific research documents, whether they are published or not. The documents may come from teaching and research institutions in France or abroad, or from public or private research centers.
L'archive ouverte pluridisciplinaire HAL, est destinée au dépôt et à la diffusion de documents scientifiques de niveau recherche, publiés ou non, émanant des établissements d'enseignement et de recherche français ou étrangers, des laboratoires publics ou privés. 
Title: Reduced risk of cancer among low-dose aspirin users: data from French healthcare databases

Running head: Reduced risk of cancer among low-dose aspirin users

A. Ajrouche ${ }^{1}$, Y. De Rycke ${ }^{1}$, M. Dalichampt ${ }^{2}$, D. Messika Zeitoun ${ }^{3}$, J. S. Hulot ${ }^{4}$, C. Estellat ${ }^{* 1}$, F. Tubach $^{* 1}$.

* contributed equally

${ }^{1}$ Sorbonne Université, Faculté de médecine Sorbonne Université, AP-HP, Hôpital PitiéSalpêtrière, Département Biostatistique Santé Publique et Information Médicale, Centre de Pharmacoépidémiologie (Cephepi), INSERM, UMR 1123, ECEVE, CIC-P 1421, F-75013 Paris, France

${ }^{2}$ Caisse nationale d'assurance maladie des travailleurs salariés cnamts, Paris, 75019, France.

${ }^{3}$ APHP, Hopital Bichat, Department of Cardiology, INSERM, UMR 1148, Paris, 75018, France. ${ }^{4}$ Sorbonne Université, Faculté de médecine Sorbonne Université, INSERM, CIC-1421, Paris, 75013, France.

CORRESPONDENCE TO: Pr Florence Tubach, Département Biostatistique Santé Publique et Information Médicale, Hôpital Pitié Salpêtrière, 47-83 Bd de l’Hôpital, 75013 Paris, France. E-mail: florence.tubach@aphp.fr

KEYWORDS- aspirin; cancer incidence; dynamic pseudo-observations; SNDS;

pharmacoepidemiology. population-based study 


\section{Key points}

- The question of the preventive effect of low-dose aspirin in the primary prevention field remains unanswered to date, with inconclusive results.

- This is the first cohort study to investigate the effect of low-dose aspirin use on overall cancer incidence and death by taking into account the competing risk of death in the presence of time dependent exposure, confounders and cumulative duration of treatment.

- Low-dose aspirin use was associated with reduced 10 -years risk of overall cancer and death, the benefits increasing with cumulative duration of low-dose aspirin use.

WORD COUNT : 3,009

\section{SUBMISSION DECLARATION}

This manuscript is an original work that has not been published and is not under consideration for publication elsewhere.

Conflict of interest:

The pharmacoepidemiology and clinical research unit (FT, CE, YD) has received research funding, grants and fees for consultant activities that have contributed indiscriminately to the salaries of its employees. DZ is consultant for Edwards LifeSciences, Mardil and Cardiawave and receive research grants from Edwards LifeSciences and Abbott vascular.

J.S H received honoria from Novartis and BMS and received a research funding from Sanofi and Servier 


\begin{abstract}
Background

The effect of chronic use of low dose aspirin (LDA) on overall cancer is still unclear owing to many controversial results and methodological limitations of studies. This study aimed to assess the effect of LDA use on overall cancer incidence among the French population.
\end{abstract}

Methods

We conducted a 10-year historical cohort study using the permanent sample of the French national healthcare databases: the Système National des Données de Santé (SNDS). We used data for 111025 individuals aged 50 to 80 years at study entry (January 1, 2006) without prevalent cancer or LDA use. Individuals were followed until the earliest of cancer incidence, death from any cause, exit from the database or end of the study on December 31,2015. We estimated the effect of LDA on cancer incidence by using a dynamic model to account for the competing risk of death in the presence of time-dependent exposure and risk factors.

Results

LDA use was associated with reduced 10-year risk of cancer (subdistribution hazard ratio [SHR] 0.81 [95\% CI 0.77-0.86]). The SHRs were 0.88 [0.82-0.94] for men and 0.93 [0.85-1.02] for women. Moreover, each additional year of LDA use was associated with reduced 10-year risk of cancer (SHR 0.93 [0.92-0.95]). LDA use was also associated with reduced 10-year risk of death (SHR $0.86[0.82-0.91])$.

\title{
Conclusion
}

This is the first population-based study to demonstrate a protective effect of LDA on overall cancer incidence and to account for the main methodological issues of previous observational studies. 


\section{Introduction}

Cancer is a worldwide growing burden in terms of morbidity, mortality and cost, with 14 million new cases in $2012^{1}$. Therefore, prevention strategies may be a promising field of research in this area ${ }^{2}$. Among those strategies, low-dose aspirin (LDA) may represent an inexpensive and effective option. Many lines of evidence have suggested a protective effect of LDA use for colorectal cancer $^{3-6}$, but recommendations regarding it use in primary prevention remain contradictory $^{4,7}$, especially because the effect of LDA on overall cancer incidence remain unclear.

The unclear effect of LDA is due to many controversial results from previous studies, together with limited follow-up from randomized trials on cancer incidence. Until now, no randomized trial testing aspirin and included overall cancer as a pre-specified outcome ${ }^{8}$ showed a benefit on cancer incidence ${ }^{8-10}$. In contrast, post-hoc analyses of randomized trials originally conducted to investigate the cardioprotective effect of LDA found a protective effect ${ }^{11}$. However, these trials were not initially designed to study cancer incidence as an outcome, and trial participants were highly selected, which limited extrapolation.

Results of observational studies were inconsistent and difficult to interpret because of high heterogeneity among studies and many methodological limitations such as immortal time bias and misclassification of exposure ${ }^{12-25}$, prothopathic bias ${ }^{22-24,26}$, inconsistency in dose and duration of use ${ }^{6}$ and competing risk of death without cancer ${ }^{27,28}$. In addition, few studies were restricted to the low aspirin dose even though it is the only relevant dose from a prevention perspective, with an established antiplatelet effect in preventing cardiovascular disease and lower rate of bleeding.

Considering all these limitations, we addressed the question of whether LDA use might be associated with reduced overall cancer incidence among the French population by using the 
Système National des Données de Santé (SNDS) national healthcare databases. In a secondary analysis, we investigated whether LDA use might be associated with a reduced prostate and breast cancer incidence, the two most common cancers among the French population ${ }^{29}$.

2. Methods (more details are presented in appendix A).

\subsection{Study overview}

We conducted a 10-year historical cohort study using the permanent sample of the national healthcare databases to estimate the effect of LDA on cancer incidence. We used a dynamic model to account for the competing risk of death in the presence of time-dependent exposure, confounders and cumulative duration of treatment.

\subsection{Data source}

The study used data from the Echantillon Généraliste des Bénéficiaires (EGB), a dynamic random sample $\left(1 / 97^{\text {th }}\right)$ in the SNDS that includes all individuals affiliated with the French health insurance system $^{30}$. The SNDS includes anonymous and prospectively recorded data on beneficiaries' characteristics, date of death, long-term chronic disease (LTD), and all out-of-

hospital health spending reimbursements ${ }^{31}$. It also contains a medical summary of each hospitalization, including hospital discharge diagnoses, medical procedures and expensive drugs dispensed during the $\operatorname{stay}^{32,33}$.

\subsection{Study population}

All individuals in the EGB sample, who were covered by the general health insurance scheme, and were 50 to 80 years old at study entry, were included in the study the January $1^{\text {st }}$, 2006. They were required to have at least 1 year of history in the database to exclude prevalent 
LDA users, defined by at least one LDA dispensed in $2005^{34}$. We also excluded individuals with any cancer but non-melanoma skin cancer (NMSC) diagnosed before study entry (at least one of the following: hospital discharge with a diagnosis of cancer; LTD status related to cancer; reimbursement for any cancer-specific drug; or external radiotherapy session). Finally, we excluded individuals who did not have sufficient follow-up (at least 1 year) for inclusion in the analysis.

\subsection{Definition of exposure}

We selected all anatomical therapeutic chemical (ATC) codes corresponding to an aspirin dose between 50 and $325 \mathrm{mg}$ (the antiplatelet dose). Definition of exposure was based on the proportion of day covered (PDC) $)^{35}$ and was modelled as a time-dependent covariate. Thus, individuals were considered not exposed from the time of study entry until they had a PDC $\geq 0.5$ during 12 consecutive months and remained exposed thereafter, according to the hypothesis of a remaining beneficial effect of LDA on cancer incidence even after discontinuation ${ }^{5}$. The 1-year cut-off for the assessment period was chosen to avoid the selection of short-term LDA users and to allow for a biologically relevant latency period. Once the individual was exposed, the duration of LDA use was calculated from the date of exposure until one calendar month after the last dispensing. We also considered alternative exposure definitions: PDC with LDA $\geq 0.8$ over 12 months and PDC with LDA $\geq 0.5$ over 24 months.

\subsection{Definition of outcomes}

Individuals were followed until the first occurrence of cancer (the main outcome) or death without cancer (the competing risk) between January 1, 2006 and December 31, 2015. Otherwise, 
individuals were censored at the last follow-up time in the database or at the closing date of the study.

Incident cancers were defined by using an algorithm validated in the EGB sample ${ }^{36}$. This algorithm combined information from outpatient and inpatient care (LTD or hospital discharge diagnosis, anticancer drugs, radiotherapy sessions, and medical procedures) and differs slightly between men and women. All cancer locations were validated, excluding NMSC.

We also considered the first occurrence of prostate and breast cancer incidence, using the same validated algorithm mentioned above, but restricted to only prostate and breast cancer codes, respectively ${ }^{36}$.

\subsection{Covariates}

On the basis of the literature, we considered the following cancer risk factors for individuals' descriptions and multivariable adjustment.

Co-morbidities included chronic obstructive pulmonary disease (COPD) and alcoholic liver cirrhosis as a proxy of heavy smoking and alcoholism, respectively, as well as diabetes mellitus. Diabetes was defined by a hospital discharge and/or LTD diagnosis of diabetes or by the presence of at least 3 reimbursements over 1 year for an antidiabetic drug. COPD and alcoholic liver cirrhosis were defined by a hospital discharge or LTD diagnosis.

Co-medications included chronic use of immunosuppressive therapy and hormone replacement therapy and each was defined by the reimbursement of at least 3 therapy deliveries over 1 year.

Health-seeking behavior was defined by the proxy number of physician visits per year and health status by the proxy number of hospital admissions per year. 
All these variables were included in the study as baseline characteristics and then modeled during follow-up as time-dependent covariates.

\subsection{Data analysis}

Baseline characteristics are described with means (SD) for continuous variables and frequency $(\%)$ for categorical variables. To assess the relationship between LDA use and cancer risk, we examined two pre-planned models: one comparing LDA users vs non-users, among the whole population, men only, and women only and one considering the cumulative duration of LDA use.

We used dynamic pseudo-observations ${ }^{37}$ to directly model the 10 -year risk of cancer and death. This model accounted for 1) the change in aspirin exposure status over time, thus circumventing the immortal time bias observed in most previous studies ${ }^{38}$; 2) time-dependent prognostic factors; and 3) the issue of the competing risk of death without cancer. We also used age as a timescale because age is an important risk factor of both cancer and death.

To apply the "dynamic pseudo-observation" model, we defined 16 landmark times $\left(\mathrm{T}_{\mathrm{LM}}\right)$ from age 50 to 80 years, equally separated by 2 years each. For each $T_{L M}$, we calculated a pseudo-observation (i.e., the contribution of each individual to the cumulative incidence function of cancer in the presence of death without cancer as a competing risk) for all individuals still at risk and we estimated the effect of all covariates on the dynamic pseudo-observations by using generalized estimating equation regression with a cloglog link function. Age-varying effects (i.e., time-varying effects such as age is used as a timescale) were identified and modeled by using fractional polynomials ${ }^{39}$. Finally, we expressed the effect of covariates on the 10-year risk of cancer and death at each landmark time as a subdistribution hazard ratio (SHR), estimating 95\% 
confidence intervals (CIs). This analysis was replicated to estimate the risk of prostate cancer and breast cancer.

In a pre-planned sensitivity analysis, we considered alternative exposure definitions.

In a post-hoc sensitivity analysis, we considered clopidogrel use (another life-long antiplatelet treatment) as a negative control ${ }^{40}$.

All analyses involved using SAS Enterprise Guide v4.3.

\section{Results}

A total of 111025 individuals aged 50 to 80 years without cancer or LDA use before study entry were included in the study (Figure 1). The mean (SD) age at inclusion was 62(8.6) years, with median follow-up 10 years, and 55\% were women (Table 1). During follow-up, 13 063 incident cancer cases (11.8\%), 8484 deaths without cancer (7.6\%) and 5805 exits from the database $(5.2 \%)$ were observed. The mean duration between the last LDA dispensing and the end of follow-up was 0.69 (1.5) years with $95 \%$ of all LDA dispensing doses ranged between 75 and $160 \mathrm{mg}$.

Results of the final model for the 60-year landmark time are in Table 2 and other landmark times are in table A.1. Overall, LDA use was associated with reduced 10-year risk of cancer (SHR 0.81[0.77-0.86], without any age-varying effect. Moreover, cumulative duration of LDA use was associated with reduced 10-year risk of cancer for every additional year of exposure (SHR 0.93[0.92-0.95] (Table 3). Covariates such as sex, diabetes and health-seeking behavior had an age-varying effect. However, the 10-year risk of cancer remained lower for women than men, and high for individuals with alcoholic cirrhosis and COPD and those taking immunosuppressive drugs, who had 6 or more physician visits or had one hospitalization in the 2 
previous years, at all landmark times. For individuals with diabetes, the risk of cancer was increased for only those aged 58 to 70 years (table A.1). LDA use was also associated with reduced 10-year risk of cancer in both sexes, statistically significant for men (SHR 0.88[0.820.94]) but not women (SHR 0.93[0.85-1.02]) (Table 2).

Moreover, LDA use was associated with reduced 10-year risk of prostate cancer (SHR $0.79[0.71-0.88]$ ), without any age-varying effect (table 4). For breast cancer, LDA use had an age-varying effect, and no significant reduction was observed (results for the 60-year landmark time are reported in table 4 and for other landmark times in table A.3). These results were heterogeneous and inconclusive given the low number of breast cancer cases at each age.

LDA use was also associated with a sustained reduction in 10-year risk of death: SHRs 0.86 [0.82-0.91] for LDA use (Table 5) and 0.95 [0.93-0.96] for every additional year of LDA use (Table 3).

Finally, in both sensitivity analyses, the results were similar for all LDA exposure definitions (Table 3) and with clopidogrel use as negative control.

\section{Discussion}

In this cohort of 111025 beneficiaries of the French national insurance system followed between 2006 and 2015, LDA use was associated with a 10-year decrease in risk of overall cancer and death, and with an incremental benefit for each additional year of LDA use. This effect was demonstrated among the general population in a real-life setting, with 10 years of follow-up and taking into account the main methodological issues of previous observational studies.

The effect of aspirin on cancer incidence remain uncertain in randomized trials ${ }^{41}$, with 2 meta-analysis showing a protective effect ${ }^{11,42}(30 \%$ reduction in cancer incidence 5 years after 
randomization, and with the benefit increasing with follow-up duration ${ }^{11}$ ), other trials showing no effect $^{9,41,43}$, and one trial with limited follow up (5 years) showing a higher risk of cancer among $\operatorname{aspirin}_{\text {users }}{ }^{4}$. However, many trials mentioned above were not designed to study cancer as an outcome. Until now, the only trial studying the effect of LDA on all-cancer occurrence as a prespecified outcome, with sufficient follow up, showed no benefit on all-cancer incidence after up to 10 years of alternate-day LDA treatment (HR $0.98[0.89-1.09])^{8}$ and a $42 \%$ reduction of colorectal cancer incidence emerged after 10 years, during the post-trial follow-up ${ }^{45}$. However, this trial was restricted to women and to an alternate-day schedule of treatment versus a daily schedule of treatment in other trials. Thus, additional follow-up from recent trials ${ }^{9,10,44}$ will be helpful to confirm a beneficial effect of aspirin on cancer incidence."

Beyond these conflicting results from randomized trials, results from previous observational studies have also been inconsistent. Interpretation and synthesis of these results was difficult because of high heterogeneity in terms of exposure definition, population included and design applied across studies ${ }^{6,21,23,25}$. As well, a protective effect of aspirin on cancer was supported more in case-control studies, which are more prone to selection and recall bias ${ }^{6,25}$. Results from cohort studies were less in favor of a protective effect but also needed to be interpreted with caution because of many methodological limitations, mainly insufficient latency period of exposure assessment ${ }^{22-24,26}$, misclassification of exposure (not considering exposure as time-dependent $)^{12-24}$, and not accounting for the competing risk of death ${ }^{27,28}$. Actually, death is expected earlier among aspirin users because of their cardiovascular disease, which would preclude the performance of some cancer diagnoses in this group, thus leading to a spurious beneficial effect of LDA on cancer.

When we restricted our analysis to the two most common cancers in France, we found a significant reduction of the 10 -year risk of prostate cancer and a non-significant reduction of the 
10-year risk of breast cancer. This could be explained by a lack of power given the low number of breast cancers at each age in the study and the age varying effect of LDA use. A nonsignificant reduction of the risk of breast cancer was also observed in a previous meta-analysis with a summary relative risk (RR) of $0.88(95 \%$ CI $0.75-1.03)$ for LDA $^{6}$. For prostate cancer, our results were consistent with previous meta-analysis of observational studies with a summary relative risk of $0.81(95 \% \text { CI } 0.69-0.95)^{6}$.

In the pre-planned subgroup analyses, we similarly found a preventive effect of LDA on the risk of cancer for both sexes, statistically significant for men but not women. This finding could be explained by an interaction with sex, with no preventive effect in women, but also by a lack of power, given the lower number of cancer cases in women. Yet, some studies found similar results ${ }^{27,28,46}$. Regardless, none of previous studies accounted for the competing risk of death and thus could be biased.

Thus, the first strength of this study was the methodology we used to counter most of the previous studies' limitations. To our knowledge, this is the first cohort study to investigate the effect of LDA use on overall cancer incidence by accounting for the competing risk of death in the presence of time-dependent exposure (thus immortal time bias), time-dependent confounders and cumulative duration of treatment, with a 10-year follow-up. Moreover, by using age as a time scale, we aimed to express all time-varying covariates as a function of age, because age is an important risk factor of cancer.

Other strengths of this study are the use of a comprehensive database representative of the French population. Information on both aspirin use and cancer were prospectively collected for an administrative purpose and thus independently of any pre-specified hypothesis. Moreover, the validated algorithm we used to identify incident cancer cases in the SNDS databases allowed us to avoid any outcome misclassification ${ }^{36}$. In addition, we restricted our study to only LDA in 
terms of clinical relevance in prevention (established antiplatelet effect in preventing cardiovascular disease and low rate of bleeding below $325 \mathrm{mg})^{47}$. Finally, the cumulative protective effect of aspirin observed for each additional year of exposure was an additional argument favoring the causality of the observed protective effect of LDA on overall cancer incidence.

However, our study also has some limitations. First, it lacks information about several cancer risk factors such as genetic factors, family history, and life-style risk factors. Yet, there is no reason to consider most of these factors as potential confounders because their distribution would not likely differ between exposed and non-exposed individuals. Unfortunately, smoking status may differ significantly between exposed and non-exposed individuals, but further adjustment on COPD to adjust for massive tobacco use did not change our results. Moreover, many previous studies have shown that the relation between aspirin and cancer incidence was independent of smoking status $27,28,46,48,49$. Finally, if any effect of tobacco use was present, as tobacco use is a cardiovascular risk factor, it would have probably attenuated the SHR toward 1, especially in men, among whom smoking is more common ${ }^{50}$, which thus reinforces our results.

Second, LDA ascertainment included only prescribed drugs, without any information on over-the-counter (OTC) use; therefore, we could have misclassified OTC users as non-exposed individuals. However, long-term OTC use is unlikely, so exposure misclassification is likely minimal. Moreover, validation studies on analogous administrative databases have shown that misclassification of LDA use due to unrecorded OTC is minimal ${ }^{51}$. Yet, to take into account that some LDA deliveries may not result in any claim, we only required a $\mathrm{PDC} \geq 0.5$. However, results remained similar even with different exposure definitions in a sensitivity analysis.

Third, we excluded non-melanoma skin cancer from our cancer definition because no previous validated algorithm in the SNDS included this cancer type in an overall cancer 
definition. This is an acceptable choice given the benign aspect of this cancer, adopted in many previous studies on overall cancer ${ }^{27,48,52,53}$.

Finally, although the effect of aspirin on overall cancer incidence may lack specificity and therefore give a combined effect of the low dose aspirin use across several cancer sites, however it remains the main public health interest in the field of cancer primary prevention. However, to further investigate this point, we assessed the effect of LDA use on prostate and breast cancer, the two most common cancers in France; yet, we lacked power to evaluate the effect of LDA on most of cancer sites. Assessing the effect of LDA on site-specific cancers would need a further study in a larger sample of the SNDS.

\section{Conclusion}

LDA use was associated with reduced 10-year risk of overall cancer and death, the benefits increasing with cumulative duration of LDA use. These results add interest in LDA as an appealing therapeutic candidate in primary prevention of cancer given its universal availability and low cost as well as cardiovascular prevention effect. 


\section{Acknowledgments:}

Funding: This work was supported by a research grant from the French ministry of health [Grant number PHRC-K 14-158]; by an academic grant from Paris Diderot University-Sorbonne Paris Cité [No grant number is applicable] to A.A.

Acknowledgments: We thank Dr David Hajage for critically reading the manuscript. 


\section{References}

1. WHO | Cancer. WHO. Available at: http://www.who.int/mediacentre/factsheets/fs297/en/. Accessed August 17, 2015.

2. WHO | Cancer prevention. WHO. Available at: http://www.who.int/cancer/prevention/en/. Accessed April 22, 2016.

3. Cole BF, Logan RF, Halabi S, et al. Aspirin for the Chemoprevention of Colorectal Adenomas: Meta-analysis of the Randomized Trials. J Natl Cancer Inst 2009; 101: 256266. doi:10.1093/jnci/djn485.

4. Aspirin Use for the Primary Prevention of Cardiovascular Disease and Colorectal Cancer: Recommendations From the U.S. Preventive Services Task Force. Ann Intern Med 2016; 164: I-22. doi:10.7326/P16-9015.

5. Rothwell PM, Wilson M, Elwin C-E, et al. Long-term effect of aspirin on colorectal cancer incidence and mortality: 20-year follow-up of five randomised trials. The Lancet 2010; 376: 1741-1750. doi:10.1016/S0140-6736(10)61543-7.

6. Bosetti C, Rosato V, Gallus S, Cuzick J, La Vecchia C. Aspirin and cancer risk: a quantitative review to 2011. Ann Oncol Off J Eur Soc Med Oncol ESMO 2012; 23: $1403-$ 1415. doi:10.1093/annonc/mds113.

7. McCarthy M. FDA questions use of aspirin for primary prevention of stroke and heart attack. BMJ 2014; 348: g3168.

8. Cook NR, Lee I-M, Gaziano JM, et al. Low-dose aspirin in the primary prevention of cancer: the Women's Health Study: a randomized controlled trial. JAMA 2005; 294: 47-55. doi:10.1001/jama.294.1.47.

9. ASCEND Study Collaborative Group, Bowman L, Mafham M, et al. Effects of Aspirin for Primary Prevention in Persons with Diabetes Mellitus. N Engl J Med 2018; 379: 15291539. doi:10.1056/NEJMoa1804988.

10. Gaziano JM, Brotons C, Coppolecchia R, et al. Use of aspirin to reduce risk of initial vascular events in patients at moderate risk of cardiovascular disease (ARRIVE): a randomised, double-blind, placebo-controlled trial. Lancet Lond Engl 2018; 392: 10361046. doi:10.1016/S0140-6736(18)31924-X.

11. Rothwell PM, Price JF, Fowkes FGR, et al. Short-term effects of daily aspirin on cancer incidence, mortality, and non-vascular death: analysis of the time course of risks and benefits in 51 randomised controlled trials. The Lancet 2012; 379: 1602-1612. doi:10.1016/S0140-6736(11)61720-0.

12. Terry MB, Gammon MD, Zhang FF, et al. Association of frequency and duration of aspirin use and hormone receptor status with breast cancer risk. JAMA 2004; 291: 2433-2440. doi:10.1001/jama.291.20.2433. 
13. Mahmud SM, Franco EL, Aprikian AG. Use of nonsteroidal anti-inflammatory drugs and prostate cancer risk: A meta-analysis. Int J Cancer 2010; 127: 1680-1691. doi:10.1002/ijc.25186.

14. Harris RE, Chlebowski RT, Jackson RD, et al. Breast cancer and nonsteroidal antiinflammatory drugs: prospective results from the Women's Health Initiative. Cancer Res 2003; 63: 6096-6101.

15. Marshall SF, Bernstein L, Anton-Culver H, et al. Nonsteroidal Anti-Inflammatory Drug Use and Breast Cancer Risk by Stage and Hormone Receptor Status. JNCI J Natl Cancer Inst 2005; 97: 805-812. doi:10.1093/jnci/dji140.

16. Swede H, Mirand AL, Menezes RJ, Moysich KB. Association of Regular Aspirin Use and Breast Cancer Risk. Oncology 2005; 68: 40-47. doi:10.1159/000084818.

17. Gill JK, Maskarinec G, Wilkens LR, Pike MC, Henderson BE, Kolonel LN. Nonsteroidal Antiinflammatory Drugs and Breast Cancer Risk: The Multiethnic Cohort. Am J Epidemiol 2007; 166: 1150-1158. doi:10.1093/aje/kwm195.

18. Danforth KN, Gierach GL, Brinton LA, et al. Nonsteroidal Anti-Inflammatory Drug Use and Endometrial Cancer Risk in the NIH-AARP Diet and Health Study. Cancer Prev Res (Phila Pa) 2009; 2: 466-472. doi:10.1158/1940-6207.CAPR-08-0239.

19. Prizment AE, Folsom AR, Anderson KE. Nonsteroidal Anti-Inflammatory Drugs and Risk for Ovarian and Endometrial Cancers in the Iowa Women's Health Study. Cancer Epidemiol Biomarkers Prev 2010; 19: 435-442. doi:10.1158/1055-9965.EPI-09-0976.

20. Bosco JLF, Palmer JR, Boggs DA, Hatch EE, Rosenberg L. Regular aspirin use and breast cancer risk in US Black Women. Cancer Causes Control 2011; 22: 1553-1561. doi:10.1007/s10552-011-9832-6.

21. Neill AS, Nagle CM, Protani MM, et al. Aspirin, nonsteroidal anti-inflammatory drugs, paracetamol and risk of endometrial cancer: A case-control study, systematic review and meta-analysis. Int J Cancer 2013; 132: 1146-1155. doi:10.1002/ijc.27717.

22. Friis S, Sørensen HT, McLaughlin JK, Johnsen SP, Blot WJ, Olsen JH. A population-based cohort study of the risk of colorectal and other cancers among users of low-dose aspirin. $\mathrm{Br}$ J Cancer 2003; 88: 684-688. doi:10.1038/sj.bjc.6600760.

23. Algra AM, Rothwell PM. Effects of regular aspirin on long-term cancer incidence and metastasis: a systematic comparison of evidence from observational studies versus randomised trials. Lancet Oncol 2012; 13: 518-527. doi:10.1016/S1470-2045(12)70112-2.

24. Verdoodt F, Friis S, Dehlendorff C, Albieri V, Kjaer SK. Non-steroidal anti-inflammatory drug use and risk of endometrial cancer: A systematic review and meta-analysis of observational studies. Gynecol Oncol 2016; 140: 352-358.

doi:10.1016/j.ygyno.2015.12.009. 
25. Qiao Y, Yang T, Gan Y, et al. Associations between aspirin use and the risk of cancers: a meta-analysis of observational studies. BMC Cancer 2018; 18: 288. doi:10.1186/s12885018-4156-5.

26. Lapi F, Levi M, Simonetti M, et al. Risk of prostate cancer in low-dose aspirin users: A retrospective cohort study: Risk of PCa in LDA users. Int J Cancer 2016; 139: 205-211. doi:10.1002/ijc.30061.

27. Cao Y, Nishihara R, Wu K, et al. Population-wide Impact of Long-term Use of Aspirin and the Risk for Cancer. JAMA Oncol 2016. doi:10.1001/jamaoncol.2015.6396.

28. Brasky TM, Potter JD, Kristal AR, et al. Non-steroidal anti-inflammatory drugs and cancer incidence by sex in the VITamins And Lifestyle (VITAL) cohort. Cancer Causes Control 2012; 23: 431-444. doi:10.1007/s10552-011-9891-8.

29. Jéhannin-Ligier K, Dantony E, Bossard N, et al. Projection de l'incidence et de la mortalité par cancer en France métropolitaine en 2017. Rapport technique. 2017.

30. Martin-Latry K, Bégaud B. Pharmacoepidemiological research using French reimbursement databases: yes we can! Pharmacoepidemiol Drug Saf 2010; 19: 256-265.

doi:10.1002/pds.1912.

31. Tuppin P, de Roquefeuil L, Weill A, Ricordeau P, Merlière Y. French national health insurance information system and the permanent beneficiaries sample. Rev Dépidémiologie Santé Publique 2010; 58: 286-290. doi:10.1016/j.respe.2010.04.005.

32. Bezin J, Duong M, Lassalle R, et al. The national healthcare system claims databases in France, SNIIRAM and EGB: Powerful tools for pharmacoepidemiology. Pharmacoepidemiol Drug Saf 2017; 26: 954-962. doi:10.1002/pds.4233.

33. Tuppin P, Rudant J, Constantinou $\mathrm{P}$, et al. Value of a national administrative database to guide public decisions: From the système national d'information interrégimes de l'Assurance Maladie (SNIIRAM) to the système national des données de santé (SNDS) in France. Rev DÉpidémiologie Santé Publique 2017; 65: S149-S167. doi:10.1016/j.respe.2017.05.004.

34. Ray WA. Evaluating medication effects outside of clinical trials: new-user designs. Am J Epidemiol 2003; 158: 915-920.

35. Centers for Medicare \& Medicaid Services (2012) Medicare Health \& Drug Plan Quality and Performance Ratings 2013 Part C \& Part D Technical Notes Centers for Medicare \& Medicaid Services. Available at: http://www.cms.gov/Medicare/Prescription-DrugCoverage/PrescriptionDrugCovGenIn/Downloads/2013C-DPlanRatings102212.zip. Accessed September 4, 2015.

36. Ajrouche A, Estellat C, De Rycke Y, Tubach F. Evaluation of algorithms to identify incident cancer cases by using French health administrative databases: Cancer incidence in the sniiram/egb databases. Pharmacoepidemiol Drug Saf 2017. doi:10.1002/pds.4225. 
37. Nicolaie MA, van Houwelingen JC, de Witte TM, Putter H. Dynamic Pseudo-Observations: A Robust Approach to Dynamic Prediction in Competing Risks: Dynamic PseudoObservations: A Robust Approach to Dynamic Prediction in Competing Risks. Biometrics 2013; 69: 1043-1052. doi:10.1111/biom.12061.

38. Suissa S. Immortal time bias in observational studies of drug effects. Pharmacoepidemiol Drug Saf 2007; 16: 241-249. doi:10.1002/pds.1357.

39. Sauerbrei W, Meier-Hirmer C, Benner A, Royston P. Multivariable regression model building by using fractional polynomials: Description of SAS, STATA and R programs. Comput Stat Data Anal 2006; 50: 3464-3485. doi:10.1016/j.csda.2005.07.015.

40. Lipsitch M, Tchetgen ET, Cohen T. Negative Controls: A Tool for Detecting Confounding and Bias in Observational Studies. Epidemiol Camb Mass 2010; 21: 383-388. doi:10.1097/EDE.0b013e3181d61eeb.

41. Zheng SL, Roddick AJ. Association of Aspirin Use for Primary Prevention With Cardiovascular Events and Bleeding Events: A Systematic Review and Meta-analysis. JAMA 2019; 321: 277-287. doi:10.1001/jama.2018.20578.

42. Sutcliffe P, Connock M, Gurung T, et al. Aspirin for prophylactic use in the primary prevention of cardiovascular disease and cancer: a systematic review and overview of reviews. Health Technol Assess 2013; 17. doi:10.3310/hta17430.

43. Chubak J, Whitlock EP, Williams SB, et al. Aspirin for the Prevention of Cancer Incidence and Mortality: Systematic Evidence Reviews for the U.S. Preventive Services Task Force. Ann Intern Med 2016; 164: 814-825. doi:10.7326/M15-2117.

44. McNeil JJ, Nelson MR, Woods RL, et al. Effect of Aspirin on All-Cause Mortality in the Healthy Elderly. N Engl J Med 2018; 379: 1519-1528. doi:10.1056/NEJMoa1803955.

45. Cook NR, Lee I-M, Zhang SM, Moorthy MV, Buring JE. Alternate-day, low-dose aspirin and cancer risk: long-term observational follow-up of a randomized trial. Ann Intern Med 2013; 159: 77-85. doi:10.7326/0003-4819-159-2-201307160-00002.

46. Jacobs EJ, Thun MJ, Bain EB, Rodriguez C, Henley SJ, Calle EE. A large cohort study of long-term daily use of adult-strength aspirin and cancer incidence. J Natl Cancer Inst 2007; 99: 608-615. doi:10.1093/jnci/djk132.

47. Cuzick J, Thorat MA, Bosetti C, et al. Estimates of benefits and harms of prophylactic use of aspirin in the general population. Ann Oncol Off J Eur Soc Med Oncol ESMO 2015; 26: 47-57. doi:10.1093/annonc/mdu225.

48. Brasky TM, Liu J, White E, et al. Non-steroidal anti-inflammatory drugs and cancer risk in women: Results from the Women's Health Initiative: NSAIDs and cancer risk in the WHI. Int J Cancer 2014; 135: 1869-1883. doi:10.1002/ijc.28823. 
49. Vaughan LE, Prizment A, Blair CK, Thomas W, Anderson KE. Aspirin use and the incidence of breast, colon, ovarian, and pancreatic cancers in elderly women in the Iowa Women's Health Study. Cancer Causes Control 2016; 27: 1395-1402. doi:10.1007/s10552016-0804-8.

50. Richard J, Beck F. Tendances de long terme des consommations de tabac et d'alcool en France, au prisme du genre et des inégalités sociales. Bull Epidémiol Hebd 2016; 126: 33.

51. Cea Soriano L, Soriano-Gabarró M, García Rodríguez LA. Validation of low-dose aspirin prescription data in The Health Improvement Network: how much misclassification due to over-the-counter use?: Over-the-counter Low-dose Aspirin in THIN. Pharmacoepidemiol Drug Saf 2016; 25: 392-398. doi:10.1002/pds.3926.

52. Bardia A, Ebbert JO, Vierkant RA, et al. Association of Aspirin and Nonaspirin Nonsteroidal Anti-inflammatory Drugs With Cancer Incidence and Mortality. JNCI J Natl Cancer Inst 2007; 99: 881-889. doi:10.1093/jnci/djk200.

53. Hollestein LM, van Herk-Sukel MPP, Ruiter R, et al. Incident cancer risk after the start of aspirin use: results from a Dutch population-based cohort study of low dose aspirin users. Int J Cancer J Int Cancer 2014; 135: 157-165. doi:10.1002/ijc.28634. 
Table 1: Baseline characteristics of the study population in 2005 overall and by sex.

\begin{tabular}{llccc}
\hline & & $\begin{array}{c}\text { Total } \\
(\mathbf{N = 1 1 1 , 0 2 5})\end{array}$ & $\begin{array}{c}\text { Men } \\
(\mathbf{N = 4 9 , 9 3 8 )}\end{array}$ & $\begin{array}{c}\text { Women } \\
(\mathbf{N = 6 1 , 0 8 7})\end{array}$ \\
\hline Characteristics & Age at study entry & $61.59(8.58)$ & $60.85(8.18)$ & $62.19(8.85)$ \\
\hline Comorbidities & COPD & $432(0.39 \%)$ & $264(0.53 \%)$ & $168(0.28 \%)$ \\
& Alcoholic liver cirrhosis & $314(0.28 \%)$ & $209(0.42 \%)$ & $105(0.17 \%)$ \\
& Diabetes & $10981(9.89 \%)$ & $4864(9.74 \%)$ & $6117(10.01 \%)$ \\
\hline Co-medications & Immunosuppressive agents & $409(0.37 \%)$ & $142(0.28 \%)$ & $267(0.44 \%)$ \\
& Hormone replacement therapy & - & - & $8647(14.16 \%)$ \\
\hline Health-seeking behavior $\dagger$ & & $8.72(9.17)$ & $6.85(8.08)$ & $10.25(9.71)$ \\
\hline Health status $\dagger$ & & $0.21(0.64)$ & $0.20(0.66)$ & $0.22(0.62)$ \\
\hline
\end{tabular}

COPD: Chronic obstructive pulmonary disease

Data are mean $(\mathrm{SD})$ for continuous variables and $\mathrm{n}(\%)$ for categorical variables

$\dagger$ at least 6 consultations over 2 years

$\$$ at least 1 hospitalization over 2 years 
Table 2: 10-year risk of cancer of the study population, overall and by sex.

\begin{tabular}{|c|c|c|c|c|c|c|c|}
\hline & & \multicolumn{2}{|c|}{ Total } & \multicolumn{2}{|c|}{ Men } & \multicolumn{2}{|c|}{ Women } \\
\hline & & $\mathrm{SHR} \uparrow$ & $95 \% \mathrm{CI}$ & $\mathrm{SHR} \dagger$ & $95 \% \mathrm{CI}$ & $\mathrm{SHR} \uparrow$ & $95 \% \mathrm{CI}$ \\
\hline $\begin{array}{l}\text { Unadjusted } \\
\text { analysis }\end{array}$ & LDA & 0.98 & {$[0.94-1.03]$} & 0.95 & {$[0.90-1.02]$} & 1.07 & {$[0.98-1.16]$} \\
\hline \multirow{9}{*}{$\begin{array}{l}\text { Adjusted } \\
\text { Analysis }\end{array}$} & LDA & 0.81 & {$[0.77-0.86]$} & 0.88 & {$[0.82-0.94]$} & 0.93 & {$[0.85-1.02]$} \\
\hline & Women vs men $\nleftarrow$ & 0.58 & {$[0.56-0.60]$} & - & - & - & - \\
\hline & Diabetes $\ddagger$ & 1.06 & {$[1.02-1.11]$} & 0.98 & {$[0.91-1.06]$} & 1.18 & [1.11-1.26] \\
\hline & Alcoholic cirrhosis & 1.62 & {$[1.31-2.00]$} & 1.73 & {$[1.37-2.20]$} & 1.45 & [0.94-2.23] \\
\hline & COPD & 1.11 & {$[0.99-1.26]$} & 1.18 & [1.03-1.36] & 0.95 & {$[0.75-1.21]$} \\
\hline & $\begin{array}{l}\text { Hormonal replacement } \\
\text { therapy }\end{array}$ & - & - & - & - & 1.14 & {$[1.05-1.24]$} \\
\hline & Immunosuppressive agents & 1.14 & {$[0.87-1.48]$} & 1.24 & {$[0.84-1.84]$} & 1.03 & {$[0.76-1.41]$} \\
\hline & Health-seeking behavior $₫ \S$ & 1.15 & [1.11-1.19] & 1.23 & [1.17-1.29] & 0.99 & [0.94-1.05] \\
\hline & Health status $\mathbb{I}$ & 1.00 & [0.97-1.04] & 1.00 & [0.96-1.05] & 0.99 & [0.95-1.04] \\
\hline
\end{tabular}

LDA: Low-dose aspirin

COPD: Chronic obstructive pulmonary disease

$\dagger$ Subdistribution hazard ratios (SHRs) at 60-year landmark time; SHR $<1(>1)$ indicates a protective (deleterious) effect of the corresponding covariate on the 10-risk of cancer

†Covariates with time-varying effects

$\S$ at least 6 consultations over 2 years

If at least1 hospitalization over 2 years 
Table 3: 10-year risk of cancer and death by LDA exposure definitions for all ages

\begin{tabular}{|c|c|c|c|c|c|c|}
\hline \multirow[b]{2}{*}{ LDA definition } & \multicolumn{3}{|c|}{ Cancer } & \multicolumn{3}{|c|}{ Death } \\
\hline & SHR & $95 \% \mathrm{CI}$ & Pvalue & SHR & $95 \% \mathrm{CI}$ & Pvalue \\
\hline $\begin{array}{l}\text { Cumulative duration for every additional } \\
\text { year of exposure } \dagger\end{array}$ & 0.93 & {$[0.92-0.95]$} & $<0.0001$ & 0.94 & {$[0.92-0.95]$} & $<0.0001$ \\
\hline PDC $\geq 0.8$ during 12 months $\ddagger$ & 0.83 & {$[0.78-0.88]$} & $<0.0001$ & 0.86 & {$[0.81-0.90]$} & $<0.0001$ \\
\hline PDC $\geq 0.5$ during 24 months $\ddagger$ & 0.80 & {$[0.76-0.84]$} & $<0.0001$ & 0.83 & {$[0.79-0.87]$} & $<0.0001$ \\
\hline
\end{tabular}

LDA: Low-dose aspirin

PDC: Proportion of day covered

$\uparrow$ Analysis with the cumulative duration of aspirin use

$\ddagger$ Sensitivity analysis 
Table 4: 10-year risk of prostate cancer and breast cancer.

\begin{tabular}{ccccccc} 
& \multicolumn{3}{c}{ Men } & \multicolumn{3}{c}{ Women } \\
& $\mathrm{N}$ & SHR & $95 \% \mathrm{CI}$ & $\mathrm{N}$ & SHR $\dagger$ & - \\
\hline Prostate cancer $\$$ & 2421 & 0.79 & {$[0.71-0.88]$} & - & - & CI \\
Breast cancer\$ & - & - & - & 2103 & 0.82 & {$[0.54-1.26]$} \\
\hline
\end{tabular}

$\dagger$ Subdistribution hazard ratios (SHRs) at 60-year landmark time; SHR < $1(>1)$ indicates a protective (deleterious) effect of the corresponding covariate on the 10-risk of cancer

tanalysis among men;

$\S$ analysis among women 
Table 5: 10-year risk of death of the study population, overall and by sex.

\begin{tabular}{|c|c|c|c|c|c|c|c|}
\hline & & \multicolumn{2}{|c|}{ Total } & \multicolumn{2}{|c|}{ Men } & \multicolumn{2}{|c|}{ Women } \\
\hline & & $\mathrm{SHR} \dagger$ & $95 \% \mathrm{CI}$ & $\mathrm{SHR} \dagger$ & $95 \% \mathrm{CI}$ & $\mathrm{SHR}_{\dagger}^{\dagger}$ & $95 \% \mathrm{CI}$ \\
\hline $\begin{array}{l}\text { Unadjusted } \\
\text { analysis }\end{array}$ & LDA & 1.10 & {$[1.05-1.16]$} & 1.10 & {$[1.02-1.18]$} & 1.12 & [1.04-1.21] \\
\hline \multirow{9}{*}{$\begin{array}{l}\text { Adjusted } \\
\text { Analysis }\end{array}$} & LDA & 0.86 & {$[0.82-0.91]$} & 0.88 & {$[0.81-0.95]$} & 0.94 & {$[0.86-1.02]$} \\
\hline & Women vs men $\nleftarrow$ & 0.55 & {$[0.47-0.65]$} & - & - & - & - \\
\hline & Diabetes & 1.49 & [1.39-1.59] & 1.91 & {$[1.24-2.96]$} & 1.49 & [1.36-1.64] \\
\hline & Alcoholic cirrhosis & 4.28 & {$[3.77-4.87]$} & 3.28 & {$[2.83-3.80]$} & 3.46 & [2.40-4.97] \\
\hline & COPD & 2.74 & [2.43-3.09] & 1.88 & {$[1.65-2.14]$} & 5.15 & [4.38-6.05] \\
\hline & $\begin{array}{l}\text { Hormonal replacement } \\
\text { therapy }\end{array}$ & - & - & - & - & 0.66 & {$[0.56-0.77]$} \\
\hline & $\begin{array}{l}\text { Immunosuppressive } \\
\text { agents }\end{array}$ & 1.37 & {$[1.07-1.75]$} & 0.92 & {$[0.59-1.42]$} & 1.67 & [1.23-2.29] \\
\hline & Health seeking behavior $\$ \S$ & 0.77 & {$[0.71-0.84]$} & 0.69 & {$[0.62-0.77]$} & 0.93 & {$[0.82-1.05]$} \\
\hline & Patient's health status & 1.27 & [1.22-1.33] & 1.57 & [1.44-1.70] & 1.30 & {$[1.22-1.38]$} \\
\hline
\end{tabular}

LDA: Low-dose aspirin

COPD: chronic obstructive pulmonary disease

$\uparrow$ Subdistribution hazard ratios (SHRs) at 60-year landmark time; SHR $<1(>1)$ indicates a protective (deleterious) effect of the corresponding covariate on the 10-risk of death

†Covariates with time-varying effects

$\S$ at least 6 consultations over 2 years

II at least1 hospitalization over 2 years 


\section{Figure legend}

Figure 1: Flow of the population in the study.

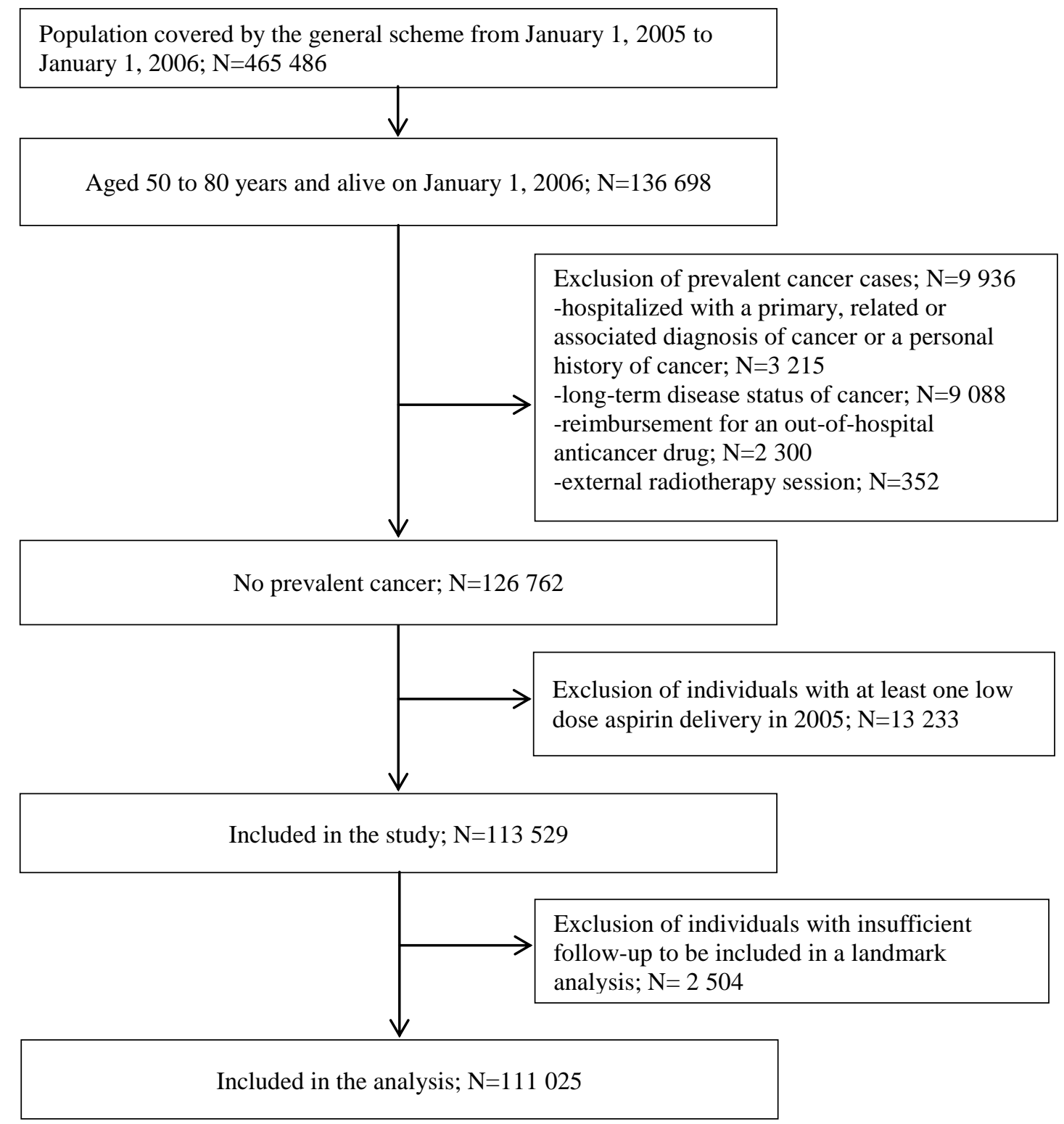


